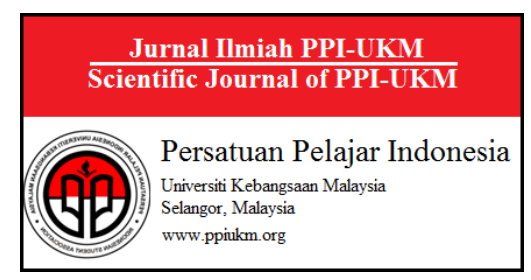

\title{
Impact of the 2015 Godzilla El Niño event on the Indonesian rainfall
}

\author{
Supari $^{\mathrm{a}, \mathrm{b} *}$, Robi Muharsyah ${ }^{\mathrm{b}}$ and Niken Wahyuni ${ }^{\mathrm{b}}$ \\ ${ }^{a}$ School of Environmental and Natural Resource Sciences, National University of Malaysia (UKM), Selangor, Malaysia \\ ${ }^{b}$ Center for Applied Climate, Indonesia Agency for Meteorology, Climatology and Geophysics (BMKG), Jakarta, Indonesia
}

\begin{abstract}
The impacts of El Niño events on the Indonesian rainfall have been documented by several earlier studies. This paper is aimed to extend the study on the El Niño impact by investigating the 2015 El Niño event, which was labelled as a "Godzilla El Niño" by NASA's climatologist. The event is unique because of its strong intensity and it was preceded by weak $2014 \mathrm{El} \mathrm{Niño.} \mathrm{We} \mathrm{analysed} \mathrm{rainfall} \mathrm{record} \mathrm{of}$ 87 stations for period 1981-2015 using percentile technique. The results show that during March 2015 - February 2016, the majority of stations recorded annual rainfall less than the $30^{\text {th }}$ percentile, a dry condition. Based on analysis of three monthly running accumulation, we found $84 \%, 89 \%$ and $78 \%$ stations recording a dry condition during July-August-September (JAS), August-September-October (ASO) and September-October-November (SON), respectively. The largest impact was observed during October 2015 where $51 \%$ stations reported the rainfall below the $10^{\text {th }}$ percentile, an extremely dry condition. Compared to 1997, the 2015 Godzilla El Niño event seems to have less impact on Indonesian rainfall even though the intensity of those two events is comparable. The number of stations experiencing dry and extremely dry condition was lower in 2015 than that in 1997, for all time scale we analysed. This may relate to the condition of sea surface temperature (SST) around Indonesia. We found that the Indonesian SST during June-November 2015 was warmer than that during 1997 indicating a more supporting condition for developing convective activity in 2015.
\end{abstract}

Keywords: El Niño, rainfall, impact, Indonesia

Received 24 April 2016; Accepted 18 July 2016

\section{Introduction}

During the 2015 dry season, there was a massive forest fire in Indonesia that burned more than 2.6 million hectares of forest, peat, and other land causing the total economic costs of more than US $\$ 16$ billion [1]. Sumatra and Kalimantan were two islands where the forest fire mainly occurred. Huge plumes of smoke spread from the fire up to neighbour countries blown by Australian monsoon wind. As a consequence, many daily activities were disrupted such as school activity and transportations.

This massive forest fire associated with the extremely dry condition over Indonesia due to the El Niño event. El Niño is a global climate anomaly caused by an above average (positive anomaly) water temperature in the Central and Eastern Tropical Pacific Ocean. Historically, El Niño occurs at irregular intervals of two to seven years. The 2015 El Niño event started to occur since the end of March 2015 as reflected by positive anomalies of sea surface temperatures (SST) across the equatorial Pacific [2]. A start of the $2015 \mathrm{El} \mathrm{Niño} \mathrm{event} \mathrm{was} \mathrm{also} \mathrm{reflected} \mathrm{by}$ the Oceanic Niño Index (ONI). This is an index used to monitor El Niño event and was calculated as the threemonth running mean of SST anomalies in the central
Pacific, namely the Niño 3.4 region. El Niño event is identified when the ONI index exceeds the threshold (0.5) for a minimum of 5 consecutive overlapping periods (http://www.cpc.ncep.noaa.gov/products/analysis_monitori ng/ensostuff/ensoyears.shtml). For the 2015 El Niño event, ONI index started to be above normal since FebruaryMarch-April (FMA, 2015) by 0.5 and reached its peak in November-December-January (NDJ). The index gradually decreased since the beginning of 2016.

The impact of El Niño events has been studied by many investigators. In general, when El Niño event occurs, there will be a drier condition in Indonesia [3] as the impact of weakening Walker circulation and cooling of Indonesian SST. For some regions where the rainfall is mainly controlled by the monsoonal system (called as a monsoonal region) the negative anomaly of rainfall might be up to $100 \%$ or totally dry [4]. However, there is a variability of the impact of El Niño event both in time and space. It was observed that the impact is more spatially coherent during the dry season than during wet season [3]. During the dry season of El Niño year, there exist the anomalous surface easterlies that reduce the local rainfall.

The impact of El Niño depends also on the intensity of the event identified by how far the anomaly of SST in the Pacific Ocean is from the normal. In the last 50 years, there were three super El Niño events where the anomaly of SST

\footnotetext{
* Corresponding author. Tel.: +6281995251300

E-mail address: supari@bmkg.go.id

DOI: $10.21752 /$ sjppi-ukm/se/a18072016
} 
in the Niño 3.4 region was more than $2.0^{\circ} \mathrm{C}$ i.e. $1982 / 1983$, 1997/1998 and 2015/2016. Kirono et al., [5] documented clearly the impact of 1997 El Niño on the Indonesian rainfall. They found that during the event, annual rainfall over Indonesia decreased up to the $10^{\text {th }}$ percentile. Moreover, many stations recorded their lowest annual rainfall on the record since 1950 .

It is interesting to understand how the newest super El Niño event impacted on Indonesian rainfall. Hence, this paper is aimed to extend the study on the El Niño impact by investigating the 2015 El Niño event. This event was labelled as a "Godzilla El Niño" by Bill Patzert, a climatologist of NASA's Jet Propulsion Laboratory to express its strong intensity [6].

\section{Data and Method}

Daily rainfall records from 87 weather stations collected by Indonesia Meteorology, Climatology and Geophysics Agency (BMKG) were used in this present study. The records cover 36 years (1981-2015). This dataset has been checked for its quality including missing values check, outliers check and homogeneity test.

We applied a rank percentile technique to analyse the impact of the 2015 El Niño event on Indonesian rainfall [5]. We computed the rank of the certain time scale in respect to the cumulative probability distribution for that given time-scale over the climatological period 1986 to 2010. We considered an analysis at four time-scales, which are annual, three monthly running total, monthly and 10day rainfall amounts. The annual rainfall total was calculated from March of the El Niño developing year up to February of the El Niño decaying year, following an approach by Kirono et al., [5]. The time scale of 10-day was used to identify in detail the start of El Niño impact. In this context, for every month, day 1 up to day 10 are considered as the first 10-day of a given month and is labelled as, for example, January-I. Day 11 up to day 20 are considered as the second 10-day and day 21 up to the end of the month are considered the third 10-day.

Based on the percentile rank we classified the rainfall into three conditions, a slight modification of classification used by the Australian Bureau of Meteorology [7]: (1) a drier condition for rainfall less than the $30^{\text {th }}$ percentile, (2) a wetter condition for rainfall more than the $70^{\text {th }}$ percentile and (3) a normal condition for rainfall recorded between those two thresholds. Additionally, we also add a label of extremely dry condition for rainfall less than the $10^{\text {th }}$ percentile. A comparison to the 1997 El Niño event was made and some similarities and differences were discussed to obtain a better understanding of the impact of super El Niño events.

\section{Results and Discussion}

\subsection{Annual rainfall}

The 2015 El Niño event is considered as strongest El Niño in our modern history based on the highest record of
Sea Surface Temperature (SST) Anomaly in central Pacific by $2.95{ }^{\circ} \mathrm{C}$ above normal during November 2015 (http://www.cpc.ncep.noaa.gov/data/indices/sstoi.indices). For the same month of the 1997 El Niño event, which is previously considered as the strongest El Niño, the SST anomaly in central pacific was $2.65{ }^{\circ} \mathrm{C}$. The evolution of SST anomaly shows that up to March 2016, the above normal SST was observed in the Pacific Ocean (central and east) extending up to the north-eastern pacific, covering a much wider area compared to 1997 event.

The annual rainfall total was seen to decrease significantly at most of the stations across the country during the 2015 El Niño event. $72 \%$ stations recorded the dry condition of annual rainfall. Furthermore, there were $41 \%$ stations with a condition of the extremely dry annual rainfall. This finding is in agreement with a study by Kirono et al., [5].

However, when compared to 1997 El Niño event, we found that annual rainfall during the 1997 event was drier than that during the 2015 event (Figure 1). During the 1997 El Niño, there were $88 \%$ stations with the dry condition of annual rainfall. The spatial distribution of these affected stations was also more coherent in 1997 , compared to the one in 2015. In addition, $72 \%$ stations were identified experiencing the extremely dry condition, a much higher number than what we found from the 2015 event. This indicates that the 1997 El Niño event caused a much larger impact than 2015 one.

Our analysis on Indonesian SST using NOAA Extended Reconstructed SST-V4 dataset [8,9] (available freely at http://www.esrl.noaa.gov/psd/) found that during JuneNovember 2015, the SST in Indonesian water was warmer than that during 1997 indicating more supporting condition for developing convective cloud in 2015 (figure not shown). It is known that the reduced Indonesian rainfall during El Niño year is partly due to the cooling of local SST [3]. This situation perhaps explained partly the reason why the 2015 El Niño event generated less impact.

\subsection{Three monthly rainfall}

Figure 2 summarizes our analysis on three monthly rainfall. Started from May-June-July (MJJ) 2015, the number of stations experiencing below the normal condition of rainfall was consistently above $50 \%$ of total stations. In MJJ, a drier condition was observed at $67 \%$ stations. This below normal rainfall condition was spatially coherent across the country. The June-July-August (JJA) rainfall also decreased obviously up to below normal condition, as recorded by $66 \%$ stations. During JulyAugust-September (JAS), August-September-October (ASO) and September-October-November (SON), the drier condition was found more coherent across the country with $84 \%, 89 \%$ and $78 \%$ stations recording below normal rainfall, respectively. 


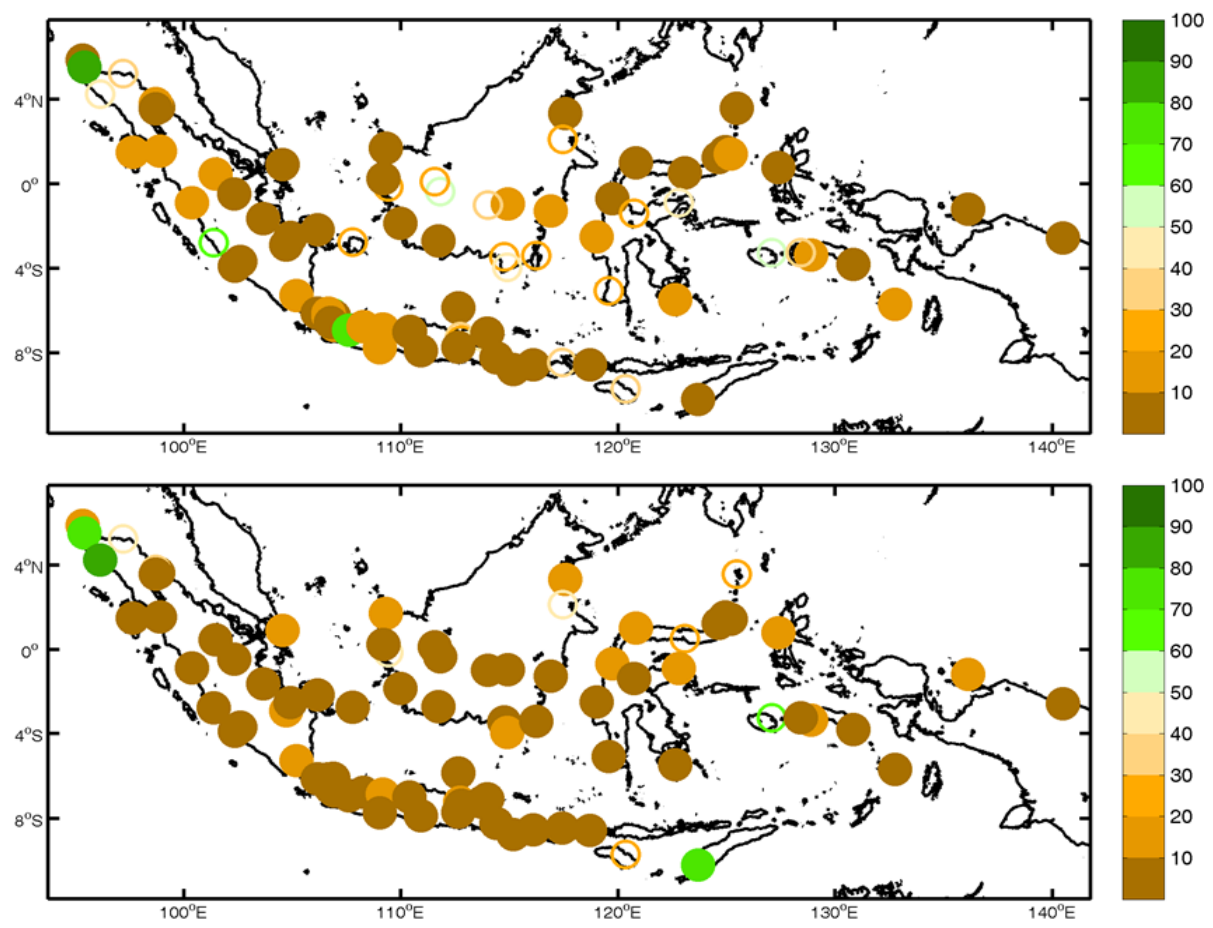

Fig. 1. The percentile rank of annual rainfall for the 2015 event (top) and the 1997 event (bottom). The open circles indicate station with normal rainfall condition $\left(30^{\text {th }}-70^{\text {th }}\right.$ percentile $)$.

Compared to that of the 1997 El Niño event, the temporal evolution of the 2015 El Niño impact on three monthly rainfall seems to be similar. Both two events had the worst impact on ASO. However, the number of stations with drier condition was always higher during 1997 event. For the El Niño of 1997, during JJA up to OND, there were more than $80 \%$ stations experiencing dry condition while for the $2015 \mathrm{El} \mathrm{Niño} \mathrm{event,} \mathrm{this} \mathrm{situation} \mathrm{only} \mathrm{occurred}$ during JAS and ASO. This comparison indicates that the 1997 El Niño event generated more serious impact on the Indonesian rainfall than the 2015 event.

Moreover, the evolution of the 2015 event was also captured from the number of stations showing extremely dry condition (rainfall $<$ the $10^{\text {th }}$ percentile). In MJJ and JJA, we identified $31 \%$ stations with extremely dry rainfall. The number of stations increased clearly in the next three months. There were $49 \%, 49 \%$ and $46 \%$ stations during JAS, ASO and SON respectively that reported rainfall amount less than the $10^{\text {th }}$ percentile. Hence, at three monthly time-scales, it is clear that the 2015 El Niño event generated most serious impact on Indonesian rainfall during JAS and ASO indicated by the highest number of stations experiencing the extremely dry condition. Interestingly, for $1997 \mathrm{El} \mathrm{Niño} \mathrm{event,} \mathrm{the} \mathrm{highest} \mathrm{number}$ of stations for this category was observed in ASO and SON, a month later than that in 2015 event.

Furthermore, the number was much higher in 1997 event i.e. $65 \%$ in ASO and $62 \%$ in SON meaning that more than half of total stations underwent an extremely dry condition. This comparison is in agreement with what we previously discussed that the 1997 El Niño event impacted on Indonesian rainfall more severely than 2015 event.

Consistent with previous studies [5], regions with a low signal of El Niño impact were also identified in this study such as Aceh and West Sumatra. Stations in Aceh even reported a condition of wetter than normal from JJA up to OND 2015. In DJF of 2016, many stations in Sumatra, Java and Kalimantan show a wetter condition. In contrast, the majority of stations in Sulawesi, Maluku, Ambon and Papua still show a drier condition. This spatial pattern suggests that the retreat of El Niño impact may start from the western part of the country.

\subsection{Monthly rainfall}

The analysis of monthly rainfall reveals that there were $43 \%$ stations reporting a condition of drier than normal in June. This number increased sharply in July i.e. $74 \%$ stations indicating the start of clear El Niño impact. In August, we observed only $47 \%$ stations with the dry condition. This is due to the increasing rainfall over Java Island during this month making monthly rainfall in this island to be a normal condition. However, the eastern part of Indonesia (Sulawesi, Maluku and Papua) still showed a dry condition during August 2015. In September and October, the dry condition was recorded at $70 \%$ and $84 \%$ stations while in November, the number was $56 \%$. The highest percentage of stations showing dry condition in October 2015 confirms that this was the driest month during 2015 El Niño event. 

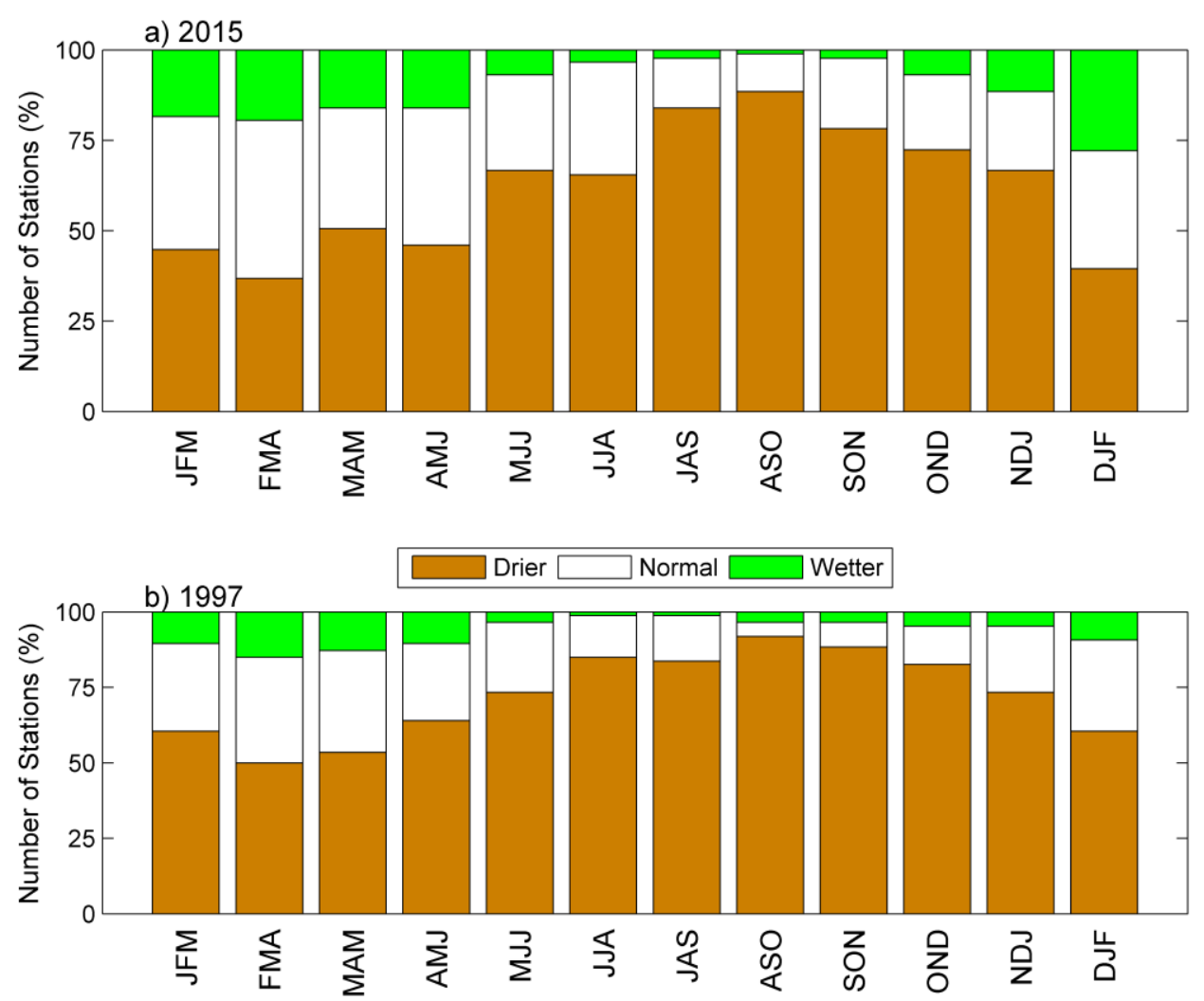

Fig. 2. The summary of three monthly rainfall analysis for the 2015 El Niño event (top) and the 1997 El Niño event (bottom). JFM means January-FebruaryMarch.

Consistently, the number of stations with less than the $10^{\text {th }}$ percentile of monthly rainfall (extremely dry condition) also had the highest value in October i.e. $51 \%$. Surprisingly, the stations with the extremely dry condition in October were mainly distributed in Sumatra, Java and Kalimantan (47\% of total stations) signalling the worst 2015 El Niño impact in the western part of Indonesia (Figure 3).

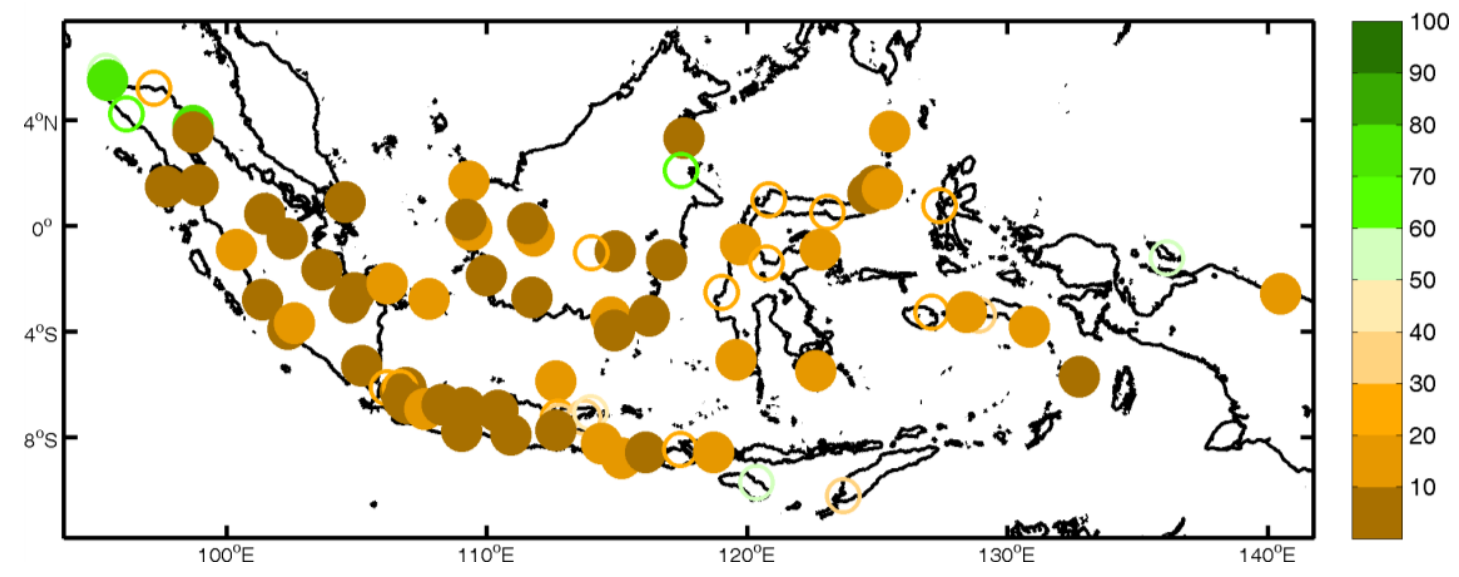

Fig. 3. The percentile rank of monthly rainfall of October 2015 with respect to the climatological period of 1986-2010. The open circles indicate station with normal rainfall condition $\left(30^{\text {th }}-70^{\text {th }}\right.$ percentile). 


\subsection{0-day rainfall amounts}

We investigated also the impact of 2015 El Niño event at a finer time-scale (i.e. 10-day rainfall total) to get an idea of the start of the impact, in detail. In the western part of Indonesia (Sumatra, Java-Bali and Kalimantan), the dry condition was observed at the majority of stations starting from the end of June (June-III). At this time, 57\% stations of this region reported a dry condition and no station was found with the wet condition. Interestingly, in the eastern part of Indonesia (Nusa Tenggara, Sulawesi, Maluku,
Ambon and Papua) the rainfall during June-III was dominated by a normal condition. Even, we found that 5 stations reported a rainfall condition of wetter than normal in this region. In the next 10-day, July-I, the 10-day rainfall amounts over the country dropped and the majority of stations (51\%) reported a dry condition (Figure 4, top panel). This pattern indicates that during July-I, almost all regions of the country were impacted by the $2015 \mathrm{El}$ Niño event. The dry condition continuously occurred until the end of October (October-III) where the $44 \%$ stations observed a rainfall condition less than the $30^{\text {th }}$ percentile.
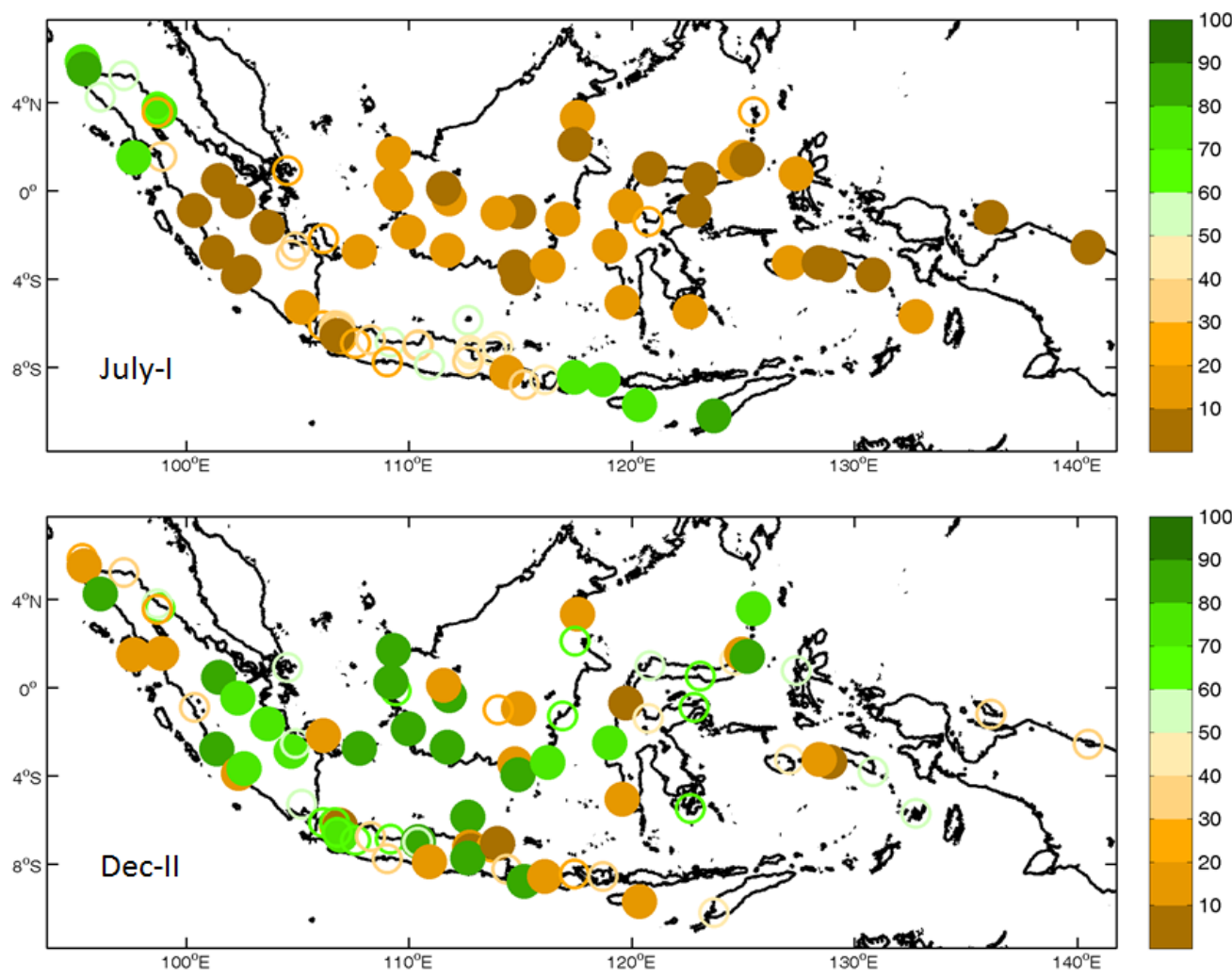

Fig. 4. The percentile rank of 10-day rainfall amounts for July-II (top) and for December-II (bottom) in respect to the climatological period of 1986-2010. The open circles indicate station with normal rainfall condition $\left(30^{\text {th }}-70^{\text {th }}\right.$ percentile).

During November 2015, many stations experienced a wet condition since the Asian winter monsoon commenced. However, the dry condition was still observed at many stations, particularly in the southern and middle part of Indonesia. In the early December (December-I), the higher number of stations with a wet condition (16\%) was observed. The number increased significantly in the mid of December (December-II) where 26\% stations reported a wet rainfall condition (Figure 4, bottom panel), particularly in the western part of Indonesia.

On the other hand, there was no clear cluster of stations with a dry condition. In fact, we observed a total of $22 \%$ stations reporting dry condition but they were distributed randomly over the country. This may indicate that in general, the impact of 2015 El Niño event on the Indonesian rainfall ended in December.

Nevertheless, it should be noted that the study of El Niño impact for every single station may result in a different conclusion. For example, some stations in West Java and Banten were observed to be dry consistently since the end of May (May-III). Another example is the case of stations in western part of Sumatra (Padang and Kerinci) that reported a consistent wet condition since the end of November (November-III). This suggests that response of local climate (as represented by single weather station) to the El Niño event is not necessarily in line with the response of regional climate. 


\section{Conclusion}

In this paper, we report our investigation on the impact of the 2015 "Godzilla" El Niño event on the Indonesian rainfall. A dataset of daily rainfall data spanning 36 years from 87 weather stations was utilized to characterize the impact. The annual rainfall dropped clearly during the 2015 El Niño event at the majority of stations. Analysis of monthly rainfall reveals that the largest impact occurred in September and October 2015. During those two months, the dry condition was observed at the majority of stations. Moreover, for October 2015, there were 51\% stations experiencing a condition of extremely dry, i.e. below the $10^{\text {th }}$ percentile. The driest regions during the peak of 2015 El Niño impact included Sumatra, Java and Kalimantan. Based on the sharp increase of the number of stations showing dry condition, we found that the impact of $2015 \mathrm{El}$ Niño event to the entire country began at the end of June (June-III). In this time, the dry condition was observed at the $57 \%$ stations. The impact continued up to the beginning of the December 2015. Comparison with the 1997 El Niño event shows that the time evolution of two events seems to be similar. However, the intensity of the impact was lesser during the 2015 El Niño reflected by the lower number of stations with the dry and extremely dry condition.

\section{References}

[1] World Bank Group, Indonesia Sustainable Landscapes Knowledge Note, 2016, p.1.

[2] NOAA, ENSO Diagnostic Discussion for March, (2015)

[3] H.H. Hendon, J Climate (2003) 16

[4] E. Aldrian, Jurnal Sains \& Teknologi Modifikasi Cuaca (2002) 3

[5] D.G.C. Kirono, N.J. Tapper, J.L. McBride, Physical Geography (1999) 20

[6] http://www.latimes.com/local/lanow/la-me-ln-el-Niño-20150813htmlstory.html

[7] http://www.bom.gov.au/climate/updates/articles/a013.shtml

[8] B. Huang, V.F. Banzon, E. Freeman, J. Lawrimore, W. Liu, T.C. Peterson, T.M. Smith, P.W. Thorne, S.D. Woodruff, and H.-M. Zhang, J Climate, (2014), in press, doi:10.1175/JCLI-D-14-00006.1

[9] W. Liu, B. Huang, P.W. Thorne, V.F. Banzon, H.-M. Zhang, E. Freeman, J. Lawrimore, T.C. Peterson, T.M. Smith, and S.D. Woodruff, J Climate, (2014) in press, doi:10.1175/JCLI-D-14-00007.1 